\title{
A FEBRE TIFOIDE NO RIO GRANDE DO SUL DA PRIMEIRA REPÚBLICA: UMA DOENÇA COM HISTÓRIA
}

\section{THE TYPHOID FEVER IN FIRST REPUBLIC RIO GRANDE DO SUL: A DISEASE WITH HISTORY}

DOI: http//dx.doi.org/10.15448/21778-3748.2018.2.26913

\author{
Fabiano Quadros Ruckert \\ Doutor em História - UFMS \\ fabianoqr@yahoo.com.br \\ Leonor Baptista Schwartsmann \\ Doutora em História - PUCRS \\ leonorschwartsmann@hotmail.com
}

\begin{abstract}
Resumo: O objetivo deste texto consiste em abordar a história da febre tifoide no Rio Grande do Sul da Primeira República. Partindo da premissa de que a febre tifoide era considerada como um importante indicativo das condições sanitárias da população, pretendemos explorar as relações entre a doença, a higiene pública e as políticas de saneamento implantadas pelo governo estadual sul rio-grandense no período entre 1889 e 1930 . Na introdução do artigo, abordamos o quadro sanitário do Rio Grande do Sul e destacamos a presença da febre tifoide nos documentos da Diretoria de Higiene do Estado; posteriormente, analisamos quatro casos epidêmicos da doença e exploramos os procedimentos adotados pelo poder público para reduzir os índices provocados pela Salmonella Typhi. Finalizando o artigo, abordamos a expansão das ações do Estado na área do saneamento expansão materializada na criação de sistemas modernos de abastecimento de água e na implantação de redes de esgoto em cidades sul rio-grandenses.
\end{abstract}

Palavras chaves: febre tifoide, Rio Grande do Sul, Primeira República.

ABSTRACT: The aim of this work is to discuss the history of typhoid fever in the State of Rio Grande do Sul during the First Republic. Considering that this disease was regarded as an important indicator of the health conditions of the population, the authors explore the relationships between the cases of typhoid fever and the status of public hygiene and health, in the light of the official sanitary policies implemented by the government of the State of Rio Grande do Sul between the years 1889 and 1930. In the introduction, the local sanitary conditions are discussed, with a special focus on the prevalence of typhoid fever, as registered by the State Directory of Hygiene. Thereafter, four typical outbreaks of the disease are presented, and then followed by the public health actions taken by the authorities to control the spread of Salmonella typhi. Finally, the authors discuss the more fundamental modifications implemented by the State to improve overall health conditions, such as the creation of modern water supply and sewage systems for the urban areas of the region.

KEYWORDS: typhoid fever, Rio Grande do Sul, First Republic. 


\section{INTRODUÇÃO}

A febre tifoide é uma doença causada pela bactéria Salmonella Typhi, presente em todo mundo. Caracteriza-se por ser uma doença bacteriana aguda, de gravidade variável que provoca febre, cefaleia, náusea, vômito, diarreia e dor abdominal, podendo ser acompanhada de erupção cutânea e dissociação pulso-temperatura. É transmitida pela ingestão de alimentos ou de água contaminados com as fezes ou urina de uma pessoa infectada. A ocorrência da doença está diretamente relacionada às condições de saneamento existentes e aos hábitos individuais de higiene. A contaminação é verificada pela manipulação dos alimentos feita por indivíduos portadores da bactéria, sendo a febre tifoide conhecida como a "doença das mãos sujas”. A água pode ser um veículo de transmissão, podendo ser contaminada no próprio manancial (rio, lago ou poço), ou mesmo na rede de distribuição quando ocorre o contato da água com resíduos cloacais infiltrados no solo.

Durante o século $\mathrm{XX}$, a incidência da doença diminuiu progressivamente devido à introdução da vacinação e de melhorias na higiene e no saneamento público. Em particular, salienta-se a cloração da água potável que produziu um impacto significativo no número de indivíduos afetados pela doença (MINISTÉRIO DA SAÚDE, 2008).

A compreensão da etiologia da febre tifoide contou com trabalhos de diversos pesquisadores, dentre os quais importa destacarmos Pierre-Fidèle Bretonneau (1778-1862); William Budd (1811-1880) e Karl Joseph Eberth (1835-1926). Em 1880, Eberth descreveu um microrganismo - o "bacilo de Eberth", depois chamado Salmonella Typhi - encontrado nos gânglios mesentéricos e no baço dos cadáveres que autopsiou. A descoberta foi confirmada por Koch, que apresentou descrição mais precisa do bacilo encontrado em cortes da parede intestinal, do baço, fígado e rim. O exame para se identificar a presença da salmonela chama-se reação de Widal e foi desenvolvido em 1896. A primeira vacina efetiva foi criada no mesmo ano e seu uso foi indicado especialmente para os membros das forças armadas.

$\mathrm{O}$ aperfeiçoamento no diagnóstico da febre tifoide ocorreu num contexto em que a antiga teoria miasmática coexistia com a emergente teoria microbiana. Explorando este contexto, dentro do qual havia uma expressiva preocupação médica com a higiene pública e um interesse da medicina pelo papel dos micróbios na transmissão das doenças, Luiz Antônio Teixeira abordou as discussões produzidas pela Sociedade de Medicina e Cirurgia de São Paulo em torno do diagnostico e da etiologia das febres que atingiam a população paulista na 
década final do século XIX (TEIXEIRA, 2004). A situação agravou-se no biênio 1896/1897, quando a Sociedade de Medicina e Cirurgia de São Paulo dividiu-se entre os que interpretavam as chamadas "febres paulistas" como variações da febre tifoide e os que discordavam dessa interpretação. Para além de uma interessante discussão científica em torno do correto diagnóstico e da etiologia das febres, o caso abordado por Teixeira nos remete para imprecisão do saber médico, aborda o impacto da microbiologia na medicina ${ }^{1}$ e ressalta o surgimento de uma crescente preocupação com o risco de transmissão do bacilo de Eberth através do consumo de águas contaminadas por dejetos humanos.

Mesmo antes da construção de um consenso científico sobre a transmissão hídrica do bacilo de Eberth, diversos profissionais da medicina advertiam para a existência de uma relação entre a falta de higiene, a precariedade no abastecimento de água e a ocorrência de epidemias de febre tifoide. Nas primeiras décadas do século passado, acreditava-se que as moscas participariam na transmissão da doença. Neste sentido, a prevenção da doença passou a ser associada com duas medidas essenciais: qualificação do saneamento e difusão das práticas de higiene.

Durante a Primeira República (1889-1930), a alta incidência de febre tifoide no Rio Grande do Sul foi considerada um problema sanitário grave, sobretudo nas cidades de Porto Alegre, Pelotas e Rio Grande. Diante do elevado número de óbitos provocados pela Salmonella Typhi nos principais núcleos urbanos do estado, o governo construiu um discurso de valorização da higiene pública e providenciou investimentos para o abastecimento de água e para coleta e descarte do esgoto (RÜCKERT, 2016).

O discurso do governo sul rio-grandense, assim como as suas ações e omissões para combate da febre tifoide, serão analisados na sequência do artigo a partir de duas perspectivas: a primeira diz respeito aos registros sobre a febre tifoide produzidos pela Diretoria de Higiene do Estado; e a segunda, contempla quatro casos de epidemias registrados na década de 1920. Dois destes casos foram localizados em documentos da própria Diretoria de Higiene (Ofícios, telegramas e descrição de procedimentos médicos); um foi estudado a partir do Relatório do Colégio Militar de Porto Alegre, referente ao ano de 1927; e um foi analisado com base em informações procedentes do Livro de Registro do Colégio São José (em Canoas) e da Tese apresentada pelo Dr. Percy Wollfenbütell para a Faculdade de Medicina de Porto Alegre, em 1930.

\footnotetext{
${ }^{1} \mathrm{O}$ impacto da microbiologia na medicina brasileira, estudado no artigo de Teixeira, também foi abordado por autores como Benchimol (1995 e 1999) e Almeida (2003), dentre outros. 
Cabe ressaltar que no Rio Grande do Sul da Primeira República, a legislação atribuía ao governo estadual a responsabilidade pela saúde pública, e atribuía aos municípios a responsabilidade pela promoção da higiene pública - o que incluía o saneamento e a fiscalização dos alimentos (SERRES; SCHWARTSMANN, 2009). No caso de ocorrência de epidemias, a intervenção do estado era realizada através da Diretoria de Higiene, mediante solicitação dos municípios.

Em 1920, a febre tifoide foi incluída na legislação federal que definia a obrigatoriedade da notificação dos casos (Decreto n. 14.354 de 1920). A legislação federal fixava os procedimentos necessários para a intervenção profilática em casos de febre tifoide, dentre os quais estavam: o aconselhamento para a vacinação antitífica, as orientações de higiene para os familiares, a profilaxia contra as moscas e a observação das condições de abastecimento de água, podendo inclusive ordenar a instalação de filtros nas residências atingidas. Para os casos de ocorrência da febre tifoide em "habitações coletivas", o afastamento do doente era recomendado.

Deve-se salientar que a utilização da vacina no estado não pode ser dissociada da política de saúde pública do Partido Republicano Rio-grandense (PRR). Conforme demonstram os estudos de Weber, o uso da vacina como recurso profilático não era uma prioridade para o PRR que, seguindo a ideologia positivista, considerava os cuidados com a saúde e a terapia das doenças como um assunto individual (WEBER, 1999). No plano discursivo, o PRR rejeitou a imposição da vacina em larga escala; mas em situações epidêmicas, usou a inoculação para conter a transmissão de determinadas doenças. Em 1918, o jornal A Federação (órgão de imprensa do PRR), publicou um editorial questionando a eficiência da vacinação antitífica ("Saúde Pública. A Federação, 4 de maio de 1918, p.1.). Naquele contexto, existia o temor de que a vacinação provocasse a predisposição para a aquisição de doenças, reativação de infecções crônicas e agravação de problemas hepáticos, cardíacos ou renais.

\section{A FEBRE TIFOIDE NOS RELATÓRIOS DA DIRETORIA DE HIGIENE DO RIO GRANDE DO SUL}

Na documentação produzida pela Diretoria de Higiene do Rio Grande do Sul, encontramos registros sobre a febre tifoide nos Relatórios enviados anualmente ao Presidente 
do Estado e na documentação administrativa da respectiva Diretoria. ${ }^{2}$ Estes registros, apesar de distintos na forma e intencionalidade, oferecem subsídios para a compreensão de como a febre tifoide foi percebida e combatida pelo governo do Partido Republicano Rio-grandense (PRR).

Nos Relatórios da Diretoria de Higiene do Estado, o primeiro registro sobre febre tifoide data de 1893 e foi escrito pelo médico Possidônio da Cunha Jr., que na ocasião, ocupava o cargo de Diretor de Higiene:

A febre tifoide, que em Londres e Berlim produziu, em 1854, por 10.000 habitantes, 10 casos fatais, número que tem baixado progressivamente, [...], a febre tifoide dá a Porto Alegre uma mortalidade de 15 indivíduos por 10.000 .

Sendo de todas as moléstias infecciosas está a que melhor pode servir de medida para apreciar a eficácia da higiene, vê-se o quanto se há de fazer aqui na cidade.

Sendo certo, quanto maior é a população em uma cidade, tanto maior são as condições favoráveis ao desenvolvimento da mortalidade, podemos concluir que, aplicando aqui os trabalhos empreendidos em bem da saúde pública nas grandes cidades, obteremos pelo menos o que lá se tem obtido. (RIO GRANDE DO SUL, 1893, p. 95).

O documento citado é um exemplo de como as autoridades sanitárias sul rio-grandense pensavam a higiene e a saúde pública a partir de experiências europeias. Observando as políticas sanitárias em curso na Europa, o governo estadual estava ciente das relações entre o saneamento e a febre tifoide e manifestava expectativas otimistas com a perspectiva de redução da doença. A partir de 1893, surgem diversos registros sobre a febre a tifoide nos documentos da Diretoria de Higiene do Estado. Os registros enfatizam a gradual redução nos óbitos provocados pela Salmonella Typhi e valorizam as iniciativas do governo estadual na promoção da higiene pública e do saneamento. Desta maneira, a diminuição da incidência da doença passou a ser considerada como parâmetro das vantagens alcançadas pela higiene agressiva que foram realizadas pelo governo estadual a partir de 1904 (SCHWARTSMANN, 2008, p. 101).

Os investimentos do governo sul rio-grandense no abastecimento de água iniciaram ainda no período imperial. Na capital do Rio Grande do Sul, a inauguração do serviço da Companhia Hidráulica Porto-Alegrense, em 1866, marcou o começo da oferta de água encanada; posteriormente, em 1891, a Companhia Hidráulica Guahybense entrou em

\footnotetext{
${ }^{2}$ A Diretoria de Higiene do Rio Grande do Sul estava subordinada à Secretaria dos Negócios do Interior e Exterior do Estado e, consequentemente, os Relatórios da respectiva diretoria integravam os Relatórios encaminhados anualmente pelo Secretário do Interior e Exterior para o Presidente do Estado.
} 
funcionamento, criando em Porto Alegre, uma concorrência no "negócio das águas" (RÜCKERT, 2016). Em Pelotas, um sistema de abastecimento de água encanada foi inaugurado pela Companhia Hidráulica Pelotense, em abril de 1875 (SILVEIRA, 2009; XAVIER, 2010). Em 1877, a cidade portuária do Rio Grande passou a contar com a água captada e distribuída pela Companhia Hidráulica Rio-grandense.

No começo da República, os investimentos no abastecimento de água foram ampliados e as municipalidades assumiram o controle do respectivo serviço. Em Porto Alegre, em 1904 a Intendência encampou a Companhia Hydráulica Guahybense e implantou um sistema público de abastecimento de água. Em Pelotas, a encampação da Companhia Hidráulica Pelotense ocorreu em 1908 e foi seguida de investimentos para ampliar a oferta de água. $\mathrm{Na}$ cidade do Rio Grande, o controle do abastecimento de água pela municipalidade efetivou-se em 1917, ano de encampação da Companhia Hydráulica Rio-grandense.

A expansão na oferta de água no começo da República foi expressiva. No entanto, antes da década de 1920, a existência de redes de água encanada estava restrita ao centro das principais cidades do estado: Porto Alegre, Pelotas e Rio Grande. Nos demais núcleos urbanos do Rio Grande do Sul, o abastecimento de água era precário e o descarte inadequado das matérias fecais era um desafio para as municipalidades. Nestas condições, a febre tifoide tornou-se uma doença recorrente nas cidades sul rio-grandenses, sobretudo nas que possuíam maior concentração demográfica.

Nos documentos da Diretoria de Higiene, a febre tifoide constantemente estava associada à qualidade das águas consumidas pela população e a gradual redução nos óbitos provocados por essa doença era considerada um resultado da ampliação na oferta de água potável. A narrativa do governo sobre a febre tifoide em Porto Alegre foi acompanhada de um discurso de valorização das obras de saneamento realizadas na capital do estado. Um exemplo deste discurso pode ser encontrado nas palavras escritas em 1920, pelo Dr. Protásio Alves, então Secretário de Estado dos Negócios do Interior e Exterior, a respeito da redução nos índices de óbito pela Salmonella Typhi.

A febre typhoide acompanhou o índice geral do quadro de letalidade. A observação da Diretoria de Higiene, mais uma vez feita, esteve de acordo com anteriores, quanto a relação existente entre o uso de água das fontes e das fornecidas por encanamentos subterrâneos. É tão grande a proporção de indivíduos, que usam água de fontes, atacados de febre typhoide, que não se pode fugir a conclusão de ser essa água vehículo principal da moléstia em Porto Alegre (RIO GRANDE DO SUL, 1920, s/p.). 
Para comprovar que a transmissão da doença estava ocorrendo através de fontes de água contaminadas, em 1920 a Diretoria de Higiene providenciou exames laboratoriais para avaliar a qualidade das águas, nos seguintes locais: Fonte Vasco da Gama; Fonte dos Freitas; Fonte do Colombo; Fonte do Pinheiro; Fonte Santa Thereza; Fonte Coronel Pacífico. Todas as fontes apresentavam sinais de contaminação por coliformes fecais e os exames reforçaram a preocupação das autoridades com a transmissão de doenças hídricas (RIO GRANDE DO SUL, 1921, s/p.).

No Relatório de 1925, a Diretoria de Higiene registrou sua convicção na relação entre o consumo de água nas fontes e os casos de febre tifoide em Porto Alegre:

Foram recebidos no referido anno, 147 notificações do mesmo mal, registrando-se 108 óbitos, na capital. [...].

A Diretoria de Higiene convencida desde o inicio de que o aparecimento da febre typhoide - não só na capital como em outras cidades do interior, era devido quase exclusivamente a origem hídrica, para tal lado tem dirigido sua attenção.

Dos diversos exames de agua, mandados proceder e pelo local de aparecimento de maior número de doentes de infecções typhicas (arrabaldes Passo da Areia, São João, Navegantes, Mont Serrat, etc), esta Diretoria, como principal medida, ordenou o fechamento dos poços e das pontes: Vasco da Gama e Freitas, tendo também marcado prazo para o fechamento da fonte do Colombo, por serem consideradas suas aguas de má qualidade, contaminadas (RIO GRANDE DO SUL, 1925, p. 329-330).

O problema das fontes de água contaminadas pela Salmonella Typhi não foi uma exclusividade de Porto Alegre. Ele existiu em outras localidades do Rio Grande do Sul na Primeira República. E o consumo de águas contaminadas foi um dos principais motivos para o constante registro de óbitos por febre tifoide nos municípios sul rio-grandenses. Cabe ressaltar que a inexistência de redes de água potável também contribuiu para a ocorrência da doença, na medida em que a falta (ou insuficiência) da água, dificultava as práticas de higiene.

Considerada uma doença endêmica pela sua recorrência, a febre tifoide tornou-se mais frequente na década de 1920 e o seu crescimento estava relacionado ao processo de urbanização que estava em curso no Rio Grande do Sul da Primeira República. ${ }^{3} \mathrm{Na}$ lista de notificações de doenças recebidas pela Diretoria de Higiene, referentes ao ano de 1928, constam 265 casos de "Febre Thyphoide e Parathyphoide". A doença preocupava as

\footnotetext{
${ }^{3}$ Acreditamos que o aprimoramento no diagnóstico das doenças facilitou a identificação dos sintomas da febre tifoide e a sua comprovação laboratorial e, consequentemente, sua notificação tornou-se mais recorrente ao longo dos anos 20.
} 
autoridades sanitárias pela facilidade da sua transmissão, pela morosidade do tratamento e pelo elevado índice de mortalidade.

Diante do aumento dos casos de febre tifoide, a Diretoria de Higiene ampliou a produção e uso da vacina antitífica. Em 1927, o Laboratório Bacteriológico da Diretoria de Higiene produziu 13.593 doses da linfa, e no ano seguinte, a produção elevou-se para 53. 382 doses. Uma parte expressiva destas vacinas foi usada na população de Porto Alegre - cidade que apresentava maior incidência nos casos de febre tifoide. Em Ofício datado de 18 de janeiro de 1928, a Diretoria de Higiene comunicou à Secretaria dos Negócios do Interior e Exterior, a decisão de ampliar a produção da vacina antitífica e registrou a seguinte observação sobre a situação da doença em Porto Alegre.

Tendo aumentado, sensivelmente, os casos de infecções typhicas, nesta Capital, ultimamente, esta Diretoria resolveu, como principal medida prophylatica, mandar proceder a vacinação anti-tífica, com vacinas preparadas em nossos laboratórios, com maior intensidade, mandando percorrer fábricas, arrebaldes São João, Navegantes e Partenhon (RIO GRANDE DO SUL. Secretaria do Interior e Exterior. AHRS, Caixa 4 maço 3. Ofício, $\mathrm{s} / \mathrm{n}^{\mathrm{o}}, 1928$ ).

O uso da vacina antitífica como medida profilática na capital do Rio Grande do Sul, apesar de circunstancial, não pode ser dissociado da crescente preocupação do governo estadual com as condições de saúde da população sul rio-grandense. Uma parte desta preocupação manifestou-se nos investimentos em projetos e obras de saneamento apoiados pelo estado, sobretudo na década de $1920 .{ }^{4}$ Outra parte, manifestou-se no aprimoramento das técnicas de estatísticas sanitárias, na fiscalização dos alimentos, na valorização da higiene como parte do currículo escolar e na política de controle da ancilostomíase adotada a partir do convênio de cooperação com a Fundação Rockefeller (KORNDÖRFER, 2007; 2013). Mas apesar da gradual ampliação das ações do estado na prevenção e controle das doenças, a política de saúde pública do PRR ao longo da Primeira República recebeu diversas críticas de setores da oposição, de órgãos da imprensa e de membros da comunidade médica. ${ }^{5}$ Foi dentro

\footnotetext{
${ }^{4}$ Segundo os números apresentados por Günter Weimer (1992), no texto A política sanitarista como diretriz de planejamento na República Velha Gaúcha, em 1928 foram investidos 36.817:104\$217 réis em saneamento no Rio Grande, do Sul. Este valor foi distribuído entre os municípios da seguinte forma: Bagé (1.194:073\$750 réis); Caxias do Sul (1.167:662\$810 réis); Cruz Alta (3.921:456\$724 réis); Itaqui (727:744\$567 réis); Pelotas (1.957: $469 \$ 520$ réis); Rio Grande (2.292:096\$820 réis); Rio Pardo (421: 056\$915 réis); Santa Maria (8:430:928\$998 réis); Santana do Livramento (3.373: 009\$973); Uruguaiana (3.807:073\$389 réis); Porto Alegre (8.474:530\$751). Cabe ressaltar que nesta lista de cidades beneficiadas, encontramos 4 que estavam ampliando os seus serviços de saneamento, são elas - Porto Alegre, Pelotas, Rio Grande e Bagé.

${ }^{5}$ As críticas à política de saúde pública do PRR, assim como as suas principais diretrizes, foram analisadas nos estudos de Weber (1999), Quaresma (2012) e Silva (2009). As pesquisas realizadas por Kummer (2002); Gill
} 
deste quadro sanitário, marcado pela insuficiência dos serviços de saúde pública no Rio Grande do Sul e pela necessidade de intervenção do estado no controle das doenças epidêmicas, que ocorreram os quatro casos de epidemia que serão destacados na sequência do artigo.

\section{EPIDEMIAS DE FEBRE TIFOIDE NO RIO GRANDE DO SUL DA PRIMEIRA REPÚBLICA}

Em julho de 1926, uma epidemia de febre tifoide atingiu 26 alunos (11\% do grupo discente) do Colégio Militar de Porto Alegre. O colégio funcionava era um internato, caracterizando-se como uma instituição de ensino e, ao mesmo tempo, como uma habitação coletiva. A faixa etária dos afetados situou-se entre 11 e 15 anos de idade, havendo um óbito. O Capitão médico, Marques Porto, confirmou que acompanhara casos esporádicos da doença anteriormente ao surto naquela instituição, e que os mesmos refletiam a situação endêmica da cidade. Porto descreveu o quadro clínico apresentado e enfatizou a forma epidêmica atual:

Essa extraordinária semelhança das formas clínicas aqui em estudo, já quando se manifestam em idênticas anomalias do traçado térmico, já na mesma fisionomia dos sintomas orgânicos, permite-nos julgá-las como manifestações de uma infecção atingindo indivíduos de uma mesma coletividade, submetidos aos mesmos métodos de vida e idêntico regime alimentar, de idades próximas, e, que contaminados no mesmo foco, isto é, atingidos pela mesma modalidade de moléstia, reagiram todos de modo semelhante (PORTO, 1926, p. 23).

Os alunos com sintomas foram recolhidos inicialmente à enfermaria do colégio. A doença foi confirmada pelos exames de hemocultura e pela Reação de Widal. Após, os mesmos foram transferidos para seus domicílios, sendo os casos mais graves encaminhados para internação no Hospital Militar. As atividades do colégio foram interrompidas pelo período de 15 dias. Foi realizado o combate sistemático às moscas e a verificação da presença de bacilíferos, ou seja, de pessoas infectadas que não apresentavam os sintomas. Para descobrir a origem da doença, também foram executados exames bacteriológicos das águas dos depósitos de água filtrada. Os exames não ajudaram a esclarecer a situação.

Seguindo a convicção de que havia uma causa hídrica do surto epidêmico e, ao mesmo tempo, de um foco permanente e ignorado de contágio, foram realizados exames bacteriológicos nas águas do poço semi-surgente localizado no pátio interno do colégio e

(2007); Korndörfer (2007 e 2013) e Schwartsmann (2008) também são obras de referência para o estudo do tema. 
encontrado a bactéria Escherichia coli. Este achado sugeriu a hipótese de contato subterrâneo entre essas águas e as matérias originadas das latrinas instaladas a 15 metros de distância do poço. Vale lembrar aqui que as águas provenientes do poço eram somente destinadas aos serviços de limpeza em geral, mas que as mesmas foram distribuídas aos alunos, quando houve a interrupção do fornecimento pela Hidráulica, burlando ordens dadas no sentido de proibir seu consumo.

Para confirmar a hipótese da transmissão hídrica da doença, foram realizadas provas colorimétricas na água do poço com a utilização de corantes nas latrinas gerais. ${ }^{6}$ Verificou-se que as águas procedentes do poço semi-surgente deram resultados positivos, sendo negativos os resultados referentes às águas das torneiras, ou seja, aquelas de procedência externa. Ficava definida a inexistência de contato entre as redes de abastecimento da água e a de esgotos. Concluiu-se que as matérias fecais originadas nas latrinas lentamente se infiltraram no terreno, poluindo o lençol de água do poço através de fissuras nos respectivos canos de esgoto. O poço foi completamente destruído após a confirmação da contaminação. Entre as medidas de profilaxia, procederam-se a adoção do copo individual, a impermeabilização do solo e a realocação dos sanitários para um local mais longínquo à cozinha e à enfermaria, seguindo orientação da Diretoria de Higiene. Os alunos foram revacinados (BRASIL, 1927).

Nas informações da epidemia circunscrita ao Colégio Militar de Porto Alegre, conseguiu-se acompanhar o raciocínio clínico e os métodos empregados para o diagnóstico da doença, aspectos de profilaxia e a investigação realizada para localização do foco de contaminação. A epidemia não foi noticiada nos jornais de circulação de Porto Alegre, presumivelmente para não causar pânico.

O segundo caso de epidemia que selecionamos para análise foi registrado no Ofício de $\mathrm{n}^{\mathrm{o}} 162$, encaminhado pela Diretoria de Higiene ao Secretário dos Negócios do Interior e Exterior, em 10 de fevereiro de 1928. O documento informa que uma equipe de três membros da Diretoria de Higiene dirigiu-se para Bella Vista $-3^{\circ}$ Distrito do município de Lajeado para auxiliar no controle de um surto de febre tifoide que estava atingindo a população do respectivo local. ${ }^{7}$ A peça mais importante do Ofício $n^{\circ} 162$ é o relatório dos procedimentos

\footnotetext{
${ }^{6} \mathrm{Na}$ prova colorimétrica são diluídos produtos químicos (corantes) de concentração conhecida. Esses corantes são utilizados para avaliação do caminho e do percurso de um determinado manancial superficial ou subterrâneo. ${ }^{7}$ É importante registrar que antes da Diretoria de Higiene iniciar sua intervenção em Lajeado, a população de Bella Vista já estava sendo atendida pelo Dr. Edward Wogl, médico designado pela municipalidade para providenciar a vacinação antitífica e socorrer os moradores atingidos pela Salmonella Typhi. Na documentação consultada, não foi possível obter dados sobre o trabalho realizado pelo Dr. Edward Wogl.
} 
encaminhados pela equipe da Diretoria de Higiene, composta pelo Dr. Mário Correa Staedter, pelo Dr. Fernando de Freitas e Castro e por um "desinfectador".

Entre o dia 01 de fevereiro de 1928 e o dia 10 do respectivo mês (data de assinatura do relatório), a equipe realizou as seguintes atividades: coletou amostras de sangue encaminhadas para exames; orientou os responsáveis pelo cuidado dos enfermos sobre a importância do asseio das mãos, objetos e roupas; tentou providenciar o isolamento dos doentes; instruiu a população sobre a necessidade de combate às moscas e aplicou a vacinação.

Com base nos relatos dos moradores de Bella Vista, o Dr. Mário Correa Staedter descreveu o histórico da epidemia, iniciada em 1926 e intensificada no decorrer de 1927. O histórico apresenta a sequência cronológica das famílias atingidas pela febre tifoide, destaca os casos de óbitos atribuídos à doença naquela localidade e registra o número de enfermos que sobreviveram em cada uma das famílias atingidas. Cabe ressaltar que o documento elaborado pelo Dr. Staedter foi baseado em relatos da comunidade de Bella Vista e, consequentemente, o número de enfermos e de óbitos atribuídos à febre tifoide deve ser ponderado, uma vez que não foram realizados exames laboratoriais para confirmar a relação entre a doença e os casos registrados pela memória da comunidade local. A leitura deste histórico indica a existência de uma relação entre as práticas de sociabilidade da comunidade rural de Bella Vista e a transmissão da doença. Em alguns casos, a visita realizada aos enfermos criou condições para que a doença atingisse outras residências.

Depois de ouvir diversos relatos sobre a evolução da doença e de realizar observações sobre as condições de higiene da comunidade de Bella Vista, o Dr. Staedter expressou sobre opinião sobre a origem daquela epidemia.

Pela maneira lenta, morosa, com que essa epidemia se manifestou, é de presumir-se que os contágios se deram directamente dos doentes aos não e, indirectamente, por meio das mãos contaminadas das pessoas que serviam de enfermeiras e que desconheciam por completo os mais simples preceitos de higiene, $[\ldots]$.

A grande quantidade de moscas existente no povoado de Bella Vista concorreu também, grandemente, para a disseminação do germe da febre typhoide, por existir sôbre o solo, em redor das habitações, grandes quantidades de material fecal de enfermos [...].

Pelas observações colhidas, é de acreditar que o lençol de água subterrâneo que alimenta os poços que abastecem o povoado de Bella Vista, não tenha sido responsável pela epidemia em questão, pois, as epidemias que tem, como fator principal a água, apresentam um outro carácter que não o da epidemia em questão, [...]. (RIO GRANDE DO SUL, Secretaria do Interior e Exterior. Ofício N.162, 1928). 
$\mathrm{Na}$ citação destacada acima, encontramos elementos para pensarmos as relações entre práticas de higiene e a salubridade. $\mathrm{O}$ desconhecimento dos preceitos de higiene entre as pessoas da comunidade de Bella Vista e a exposição do "material fecal" dos enfermos às moscas criariam as condições necessárias para a difusão da febre tifoide. Considerando estes fatos e o ritmo lento de propagação da doença, o Dr. Staedter rejeitou a possibilidade contaminação das águas subterrâneas. ${ }^{8}$ Ele considerou que a transmissão da Salmonella Typhi ocorrera pelos hábitos higiênicos inadequados e pela interferência de indivíduos portadores assintomáticos da doença.

A epidemia de febre tifoide em Lajeado pode ser considerada uma das mais graves registradas nos documentos da Diretoria de Higiene no Rio Grande do Sul: mais de 100 pessoas foram contaminadas, sendo que 17 faleceram em decorrência da febre tifoide; todos os membros de famílias atingidas foram vacinados e outras 375 pessoas também receberam a vacina antitífica durante os dez primeiros dias do mês de fevereiro de $1928 .{ }^{9} \mathrm{O}$ trabalho de intervenção na epidemia, realizado pela Diretoria de Higiene do Estado, também incluiu a distribuição de panfletos, a proibição do "lançamento de dejetos humanos sobre o solo", a desinfecção de terrenos na vizinhança das residências atingidas pela doença, a desinfecção de roupas e colchões dos enfermos e a extinção das moscas (RIO GRANDE DO SUL, Secretaria do Interior e Exterior, Ofício No 162, 1928).

O terceiro caso de epidemia que localizamos nas fontes documentais ocorreu na cidade de Encruzilhada. Nos primeiros meses de 1928, a cidade foi atingida pela febre tifoide e a municipalidade recorreu ao auxílio da Diretoria de Higiene para providenciar a vacinação e prevenir a transmissão da doença. A resposta do governo estadual foi registrada no Ofício 333, de 17 de março de 1928. No Ofício, o Diretor de Higiene informou ao Secretário dos Negócios do Interior e Exterior que havia encaminhado duas remessas da linfa para Encruzilhada: a primeira de 150 caixas, e a segunda de 250. Seguindo o procedimento padrão de interferir nos casos de epidemia, a Diretoria de Higiene enviou para Encruzilhada o médico auxiliar Dr. Piaguaçú Correa e o auxiliar de Laboratório Enio Marsiaj.

O primeiro com instruções de tomar todas as medidas prophylacticas aconselhadas em taes casos, procurar saber como propagou-se o mal ali, e,

\footnotetext{
${ }^{8}$ O Dr. Staedter estava convicto de que a transmissão da Salmonella Typhi não havia ocorrido pela água e por isso não providenciou exames laboratoriais que poderiam comprovar a situação química das águas subterrâneas na localidade de Bella Vista.

${ }^{9}$ A vacinação também foi aplicada em moradores do Distrito de Gramado, localizado ao lado do Distrito de Bella Vista, e nas comunidades de Gravino e Marques de Souza.
} 
principalmente, proceder, com intensidade, a vacinação typhica e paratyphica em todos os munícipes, medida esta, encarada hoje em dia, como principal em casos idênticos.

O segundo, o auxiliar bacteriologista, levou consigo material para colher amostra das águas que se abastecem a população e proceder a semeadura in loco, para os respectivos exames bacteriológicos (RIO GRANDE DO SUL, Secretaria do Interior e Exterior, Ofício N. 333, 1928).

Os trabalhos realizados pela Diretoria de Higiene na cidade de Encruzilhada foram registrados no telegrama enviado pelo Dr. Piaguaçú para Porto Alegre. Com base neste telegrama, sabemos que a vacinação foi intensificada e que as pessoas envolvidas no tratamento dos pacientes receberam orientações para evitar a transmissão da doença durante o atendimento aos enfermos. Os profissionais da Diretoria de Higiene realizaram a desinfecção das residências atingidas pela febre tifoide e desinfetaram "habitações collectivas, tais como: hoteis, collegios, quarteis, etc.” O Dr. Piaguaçú observou a situação sanitária da cidade e afirmou que as fontes de água que abasteciam a população estavam em "péssimas condições de hygiene". Para confirmar a possibilidade de transmissão hídrica da Salmonella Typhi, amostras de água das fontes foram coletadas e encaminhadas para exames laboratoriais em Porto Alegre (RIO GRANE DO SUL, Secretaria do Interior e Exterior, Telegrama do Dr. Piaguaçú, 1928).

Comparando a epidemia de Bella Vista com a epidemia de Encruzilhada, podemos identificar semelhanças nos procedimentos da Diretoria de Higiene e, ao mesmo tempo, podemos observar diferenças. No caso de Encruzilhada, o Dr. Piaguaçú considerou a possibilidade da febre tifoide ser transmitida pelas fontes de água que abasteciam a cidade. Em Bella Vista, o Dr. Staedter descartou a possibilidade de transmissão hídrica e considerou as moscas e a falta de higiene da população como os motivos da ocorrência da febre tifoide. Quantitativamente, as duas epidemias foram diferentes: em Bela Vista foram mais de 100 contaminados, enquanto que em Encruzilhada, foram apenas 12. Cada um destes casos de epidemia produziu experiências singulares nos locais onde ocorreu. No pequeno povoado de Bella Vista, a Salmonella Typhi fez vítimas mortais em diversas famílias e o socorro médico tardou para chegar. Na cidade de Encruzilhada, a mobilização da Intendência e do governo estadual para aplicar a vacina em larga escala, resultaram no rápido controle da doença.

A intervenção profilática do governo estadual é um aspecto em comum nos casos de epidemias de febre tifoide destacados anteriormente. A mesma intervenção foi observada no 
surto de febre tifoide ocorrido em 1927, no Colégio São José, em Canoas. ${ }^{10}$ Nos documentos dos irmãos salesianos, responsáveis pela administração daquela instituição de ensino, a ocorrência da febre tifoide foi registrada nos seguintes termos:

Tudo corria bem, quando, pelos meados de março, aprouve a Deus provarnos com a terrível epidemia de tifo, 27 jovens foram mais ou menos fortemente atacados. A epidemia grassou com certa intensidade até fins de abril. Tivemos a dor de perder um dos nossos melhores noviços, com 23 anos de idade. [...].

Por medida de higiene geral, desde fevereiro já se iniciara a construção de reformas reconhecidas indispensáveis; principalmente foi a construção de latrinas patentes em substituição das simples fossas [...].

Provavelmente, devido a estas medidas de precaução tomada é que os senhores encarregados da higiene do Estado nos testemunharam toda benevolência possível (COLÉGIO SÃO JOSÉ, Histórico, Livro 1, 1927, $\mathrm{s} / \mathrm{p}$.).

O documento citado registra a preocupação dos irmãos salesianos com as instalações sanitárias existentes no Colégio. Ele também registra a presença dos "encarregados da higiene do Estado", ou seja, dos profissionais encaminhados pela Diretoria de Higiene para atacar a epidemia que estava em curso. Um destes profissionais foi o Dr. Freitas e Castro. Com base nas investigações que realizou para apurar a origem da epidemia, o Dr. Freitas e Castro constatou que não foram as águas do poço do Colégio que provocaram a doença, e sim, as águas de um poço localizado em uma Chácara visitada por um grupo de alunos, na semana anterior ao surgimento dos primeiros casos (WOLLFENBÜTTEL, 1930, p. 27).

\section{CONSIDERAÇÕES FINAIS}

O estudo das epidemias de febre tifoide revela a maneira como as autoridades públicas e a população sul rio-grandense posicionavam-se diante das doenças. Em relação a historicidade dos casos de epidemia, Burguiére (1998, p. 140) afirma que:

[...] reconstituir a história de um fenômeno epidêmico é analisar a maneira como a organização e as normas culturais de uma sociedade puderam digerir as injunções do meio natural e enfrentá-las, é ressaltar a problemática social e as formas de relação com o corpo que cada época expressa através de seus componentes biológicos.

\footnotetext{
${ }^{10}$ No período de 1908 a 1925, o Colégio São José foi um internato A partir de1926 ele tornou-se um seminário, coordenado pelos irmãos salesianos (NESELLO, 2011, p.44). Canoas, na época, era distrito de Gravataí e o seu centro histórico (em torno do prédio do antigo Colégio São José) era um local "bucólico, simples e pequeno", conforme diversos depoimentos e imagens da época (PENNA, 2004, p. 24-26).
} 
Corretamente, Burguiére indica a existência de relações entre epidemias, "normas culturais", "formas de relação com o corpo" e "a problemática social". Nas quatro epidemias de febre tifoide, destacadas neste artigo, a insuficiência das práticas de higiene, a precariedade das instalações sanitárias e o descuido com a qualidade das águas consumidas podem ser consideradas "normas culturais" que contribuíram para a transmissão da Salmonella Typhi.

No que diz respeito às "formas de relação com o corpo", registradas nas fontes documentais consultadas, percebemos a ocorrência de dois tipos de intervenção médica: uma preventiva, voltada para o corpo dos que não estavam contaminados pela doença, e outra curativa, focada nos cuidados necessários para auxiliar a recuperação dos enfermos. A documentação pesquisada, também nos permitiu observar a coexistência de diferentes níveis de preocupação com o corpo do enfermo: os médicos estavam cientes do possível risco de contaminação das pessoas que atendiam os contaminados e recomendavam o isolamento dos enfermos; no entanto, as práticas de sociabilidade da época envolviam os familiares responsáveis pela higiene e medicação dos enfermos - e incluíam as tradicionais visitas de vizinhos e amigos.

$\mathrm{Na}$ opinião dos médicos, as precárias condições de higiene da população, a má qualidade das águas consumidas e a prática de visita aos enfermos - contribuíram para agravar a disseminação da febre tifoide. Estamos então diante de fragmentos históricos de uma "problemática social", na medida em que a educação sanitária e a promoção da higiene pública com obras e serviços de saneamento eram assuntos de interesse social e, ao mesmo tempo, eram responsabilidades do poder público.

\section{REFERÊNCIAS BIBLIOGRÁFICAS}

ALMEIDA, Marta de. República dos invisíveis: Emílio Ribas, microbiologia, e saúde pública em São Paulo 1898-19171. São Paulo, Editora Universitária São Francisco, 2003.

BENCHIMOL, Jaime Larry. Domingos José Freire e os Primórdios da Bacteriologia no Brasil. História, Saúde, Ciências - Manguinhos, II (1): 67-98, mar - jun, 1995.

. Dos micróbios aos mosquitos: febre amarela e revolução pasteuriana no Brasil. Rio de Janeiro, Fiocruz/Editora da UFRJ, 1999. 
BURGUIÉRE, André. A antropologia histórica. In: Le Goff, Jacques (org.) A História Nova. São Paulo: Martin Fontes, 1998.

GILL, Lorena. O mal do século: tuberculose, tuberculosos e políticas de saúde pública em Pelotas (RS) 1890-1930. Pelotas: EDUCAT, 2007.

KORNDÖRFER, Ana Paula. "Melhor prevenir do que curar": a higiene e a saúde nas escolas públicas gaúchas (1893-1928). Dissertação de Mestrado em História, São Leopoldo:

UNISINOS, 2007. Disponível em:

$<$ http://biblioteca.asav.org.br/vinculos/tede/melhor\%20prevenir.pdf $>$ Acesso em: junho de 2013.

KORNDÖRFER, Ana Paula. “An international problem of serious proportions.” A cooperação entre e a Fundação Rockefeller e o governo do Estado do Rio Grande do Sul no combate à Ancilostomíase e seus desdobramentos (1919-1929). Tese de Doutorado em História, Porto Alegre: PUCRS, 2013. Disponível em:

$<$ http://tede.pucrs.br/tde arquivos/15/TDE-2013-05-14T053823Z-4453/Publico/448009.pdf> Acesso em: setembro de 2014.

KUMMER, Lizete Oliveira. A medicina social e a liberdade profissional: os médicos gaúchos na Primeira República. Dissertação de Mestrado em História, Porto Alegre: Universidade Federal do Rio Grande do Sul - UFRGS 2002. $<\underline{\text { https://www.lume.ufrgs.br/bitstream/handle/10183/3577/000340264.pdf? sequence=1 }>}$

MINISTÉRIO DA SAÚDE. Departamento de vigilância epidemiológica. Manual integrado de vigilância e controle. Febre tifoide. Série A. Normas e Manuais técnicos. Brasília. 2008. Disponível em:

$<\underline{\text { http://www.bvsms.saude.gov.br/bvs/publicacoes/manual vigilancia controle febre tifoidel. }}$ pdf> Acesso em: maio de 2016.

NESELLO, Norberto Luiz. La Salle: 100 anos de presença em Canoas/RS. Canoas: La Salle, 2011. 
PENNA, Rejane (coord.). Canoas - para lembrar quem somos. Centro. 2 ed. Canoas: La Salle, 2004.

QUARESMA, Paulo Sérgio Andrade. Urbe em tempos de varíola: a cidade do Rio Grande (RS) durante a epidemia de 1904-1905. Dissertação de Mestrado em História, Pelotas: UFPEL, 2012. Disponível em:

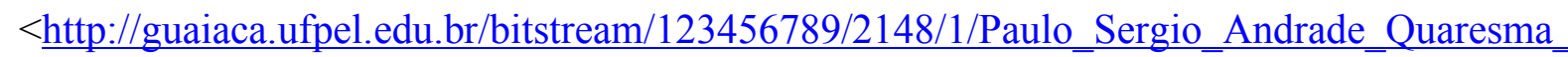
Dissertacao.pdf> Acesso em: abril de 2016.

RÜCKERT, Fabiano Quadros. O saneamento e a politização da higiene no Rio Grande do Sul (1828-1930). Tese de Doutorado em História, São Leopoldo: UNISINOS, 2016.

SCHWARTSMANN, Leonor B. Olhares do médico viajante Giovanni Palombini no Rio Grande do Sul (1901-19014). Porto Alegre: EDIPUCRS, 2008.

SERRES, Juliane C. Primon; SCHWARTSMANN, Leonor. (Orgs.) História da Medicina: instituições e práticas de saúde no Rio Grande do Sul. Porto Alegre: EDIPUCRS, 2009.

SILVA, Raquel Padilha da. A Cidade de Papel: a epidemia de peste bubônica e as críticas em torno da saúde pública na cidade do Rio Grande (1903-1904). Tese de Doutorado em

História, Porto Alegre: PUCRS, 2009.

SILVEIRA, Aline Montagna da. De fontes e aguadeiros à penas d'água. Reflexões sobre o sistema de abastecimento de água e as transformações da arquitetura residencial no final do século XIX em Pelotas, RS. Tese de Doutorado em Arquitetura, São Paulo: USP, 2009.

TEIXEIRA, Luiz Antônio. As febres paulistas na Sociedade de Medicina e Cirurgia de São Paulo: uma controvérsia entre porta-vozes de diferentes saberes. História, Ciências, Saúde Manguinhos, vol. 11 (suplemento 1): 41-66, 2004.

XAVIER, Janaina Silva. O saneamento em Pelotas (1871-1915): o patrimônio sob o signo de modernidade e progresso. Dissertação de Mestrado em Memória Social e Patrimônio Cultural, Pelotas: Universidade Federal de Pelotas, 2010. Disponível em: 


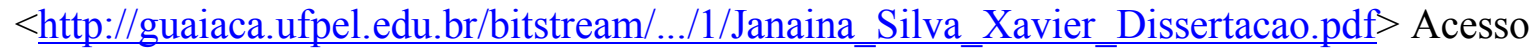
em: outubro de 2015.

WEBER, Beatriz Teixeira. As artes de curar: Medicina, Religião, Magia e Positivismo na República Rio-Grandense, 1889/1928. Santa Maria: Ed. da UFSM; Bauru: EDUSC - Editora da Universidade do Sagrado Coração, 1999.

WEIMER, Günter. A Política Sanitarista como Diretriz de Planejamento na República Velha Gaúcha. In: WEIMER, Günter (Org.). Urbanismo no Rio Grande do Sul. Porto Alegre: UFRGS, p. 93-109, 1992.

\section{FONTES DOCUMENTAIS}

COLÉGIO SÃO JOSÉ. Histórico, Livro 1 [manuscrito], 1927.

BRASIL. Relatório do Colégio Militar de Porto Alegre apresentado ao Exmo. Sr.

General Nestor Sezefredo dos Passos, Ministro de Estado dos Negócios de Guerra. Porto Alegre: 1927.

RIO GRANDE DO SUL. Relatório apresentado ao Presidente do Estado do Rio Grande do Sul, em 15 de setembro de 1893, pelo Secretário de Estado Interino dos Negócios do Interior e Exterior, Possidonio M. da Cunha Junior”. Porto Alegre: Officinas graphicas d’A Federação, 1893.

RIO GRANDE DO SUL. Relatório apresentado ao Dr. A. A. Borges de Medeiros Presidente do Rio Grande do Sul pelo Engenheiro Ildefonso Soares Pinto - Secretário do Estado dos Negócios das Obras Públicas em 06 de Agosto de 1920. Porto Alegre: Officinas Graphicas d'A Federação, 1920.

RIO GRANDE DO SUL. Relatório apresentado ao Sr. A. A. Borges de Medeiros pelo Dr. Protásio Alves em 30 de agosto de 1921. Porto Alegre: Officinas Graphicas d' A Federação, 1921. 
RIO GRANDE DO SUL. Relatório apresentado ao Exmo Sr. Dr. A. A. Borges de Medeiros presidente do Estado do Rio Grande do Sul pelo Dr. Protásio A. Alves. Secretário de Estado dos Negócios do Interior e Exterior. Porto Alegre: Officinas Graphicas d' A Federação. 1925.

RIO GRANDE DO SUL. Secretaria do Interior e Exterior. AHRS, Caixa 4 - maço 3. Ofício, $\mathrm{s} / \mathrm{n}^{\mathrm{o}}, 1928$.

RIO GRANDE DO SUL. Secretaria do Interior e Exterior, Relatório do Dr. Mário Correa Staedter. AHRS, Caixa 4, maço 3. Ofício No 162, 1928.

RIO GRANDE DO SUL. Secretaria do Interior e Exterior. AHRS, Caixa 4, maço 3. Ofício No 333, 1928.

RIO GRANDE DO SUL. Secretaria do Interior e Exterior, Telegrama enviado pelo Dr. Piaguaçú ao Diretor de Higiene. AHRS, Caixa 4, maço 3, 1928.

PORTO, Marques. Aspectos clínicos e profiláticos de uma epidemia de febre tifoide. Archivos Rio-Grandenses de Medicina. Porto Alegre, ano V, nº1, 15 set 1926.

WOLLFENBÜTELL, Percy. Contribuição ao estudo das febres typhicas e para-typhicas em Porto Alegre. These apresentada a Faculdade de Medicina de Porto Alegre em 30 de Novembro de1930, Porto Alegre: Officinas Graphicas da Livraria do Globo, 1930. 